\title{
Article \\ Splatters and Aerosols Contamination in Dental Aerosol Generating Procedures
}

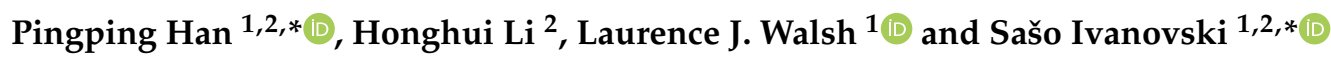 \\ 1 School of Dentistry, Faculty of Health and Behavioural Sciences, The University of Queensland School of \\ Dentistry, Brisbane, QLD 4006, Australia; 1.walsh@uq.edu.au \\ 2 Epigenetics Nanodiagnostic and Therapeutic Group, Center for Oral-Facial Regeneration, Rehabilitation and \\ Reconstruction (COR3), School of Dentistry, Faculty of Health and Behavioural Sciences, The University of \\ Queensland, Brisbane, QLD 4006, Australia; honghui.li@uq.net.au \\ * Correspondence: p.han@uq.edu.au (P.H.); s.ivanovski@uq.edu.au (S.I.); Tel.: +61-7-336-58064 (P.H.)
}

Citation: Han, P.; Li, H.; Walsh, L.J.; Ivanovski, S. Splatters and Aerosols Contamination in Dental Aerosol Generating Procedures. Appl. Sci. 2021, 11, 1914. https://doi.org/ 10.3390/app11041914

Academic Editor: Luca Testarelli

Received: 21 January 2021

Accepted: 12 February 2021

Published: 22 February 2021

Publisher's Note: MDPI stays neutral with regard to jurisdictional claims in published maps and institutional affiliations.

Copyright: (c) 2021 by the authors. Licensee MDPI, Basel, Switzerland. This article is an open access article distributed under the terms and conditions of the Creative Commons Attribution (CC BY) license (https:/ / creativecommons.org/licenses/by/ $4.0 /)$.

\begin{abstract}
Dental aerosol-generating procedures produce a large amount of splatters and aerosols that create a major concern for airborne disease transmission, such as COVID-19. This study established a method to visualise splatter and aerosol contamination by common dental instrumentation, namely ultrasonic scaling, air-water spray, high-speed and low-speed handpieces. Mock dental procedures were performed on a mannequin model, containing teeth in a typodont and a phantom head, using irrigation water containing fluorescein dye as a tracer. Filter papers were placed in 10 different locations to collect splatters and aerosols, at distances ranging from 20 to $120 \mathrm{~cm}$ from the source. All four types of dental equipment produced contamination from splatters and aerosols. At $120 \mathrm{~cm}$ away from the source, the high-speed handpiece generated the greatest amount and size $(656 \pm 551 \mu \mathrm{m})$ of splatter particles, while the triplex syringe generated the largest amount of aerosols (particle size: $1.73 \pm 2.23 \mu \mathrm{m}$ ). Of note, the low-speed handpiece produced the least amount and size $(260 \pm 142 \mu \mathrm{m})$ of splatter particles and the least amount of aerosols (particle size: $4.47 \pm 5.92 \mu \mathrm{m})$ at $120 \mathrm{~cm}$. All four dental AGPs produce contamination from droplets and aerosols, with different patterns of distribution. This simple model provides a method to test various preventive strategies to reduce risks from splatter and aerosols.
\end{abstract}

Keywords: dental aerosol-generating procedures; COVID-19; splatter; droplets; aerosols; dental procedures

\section{Introduction}

The generation of aerosol and splatter creates a major risk for airborne contamination within the clinical environment [1-4]. Most routine dental treatments are aerosolgenerating procedures (AGPs) that produce a mixture of splatter, droplets and aerosols that contain saliva, blood, irrigant water, and viable microorganisms (including bacteria and viruses) $[1,5]$. Commonly used dental instruments, including dental handpieces, airwater (triplex) syringes, and ultrasonic scalers all generate a large volume of splatter and aerosols, that are derived from patient fluids and coolant water, and that pose a risk to dental professionals and patients $[1,5,6]$. In order to assess the benefit of any protective methods or devices, it is first necessary to visualise very small amounts of contamination from splatter and aerosols during dental procedures. Such microdroplets are invisible and hence special methods are needed to visualise them and to map their spatial distribution within the working environment, and hence develop better ways to mitigate the risk of disease transmission.

There is an ongoing discussion in the literature on how to best define aerosols, droplets and splatter [7,8]. For the present study, splatter was defined as large liquid particles with the size $\geq 100 \mu \mathrm{m}$ [9], whereas, droplets are medium size particles in the range of 5-100 $\mu \mathrm{m}[10]$, and aerosols are $\leq 5 \mu \mathrm{m}[11,12]$. The splattered fluid is large airborne 
particles, and these fall onto surfaces in the dental operatory under the influence of gravity, following a ballistic trajectory from the point of origin. In contrast, droplets can remain suspended in the air until their water evaporates, and aerosols can remain suspended for several hours (depending on local air movement) and can travel for 1-3 $\mathrm{m}$ from their source [13].

Dental splatter, droplets and aerosols may contain pathogenic oral bacteria, nanoparticles [6,14-16], as well as respiratory viruses (including adenoviruses, influenza viruses, and the SARS-CoV-2 coronavirus [6,17]). Much greater attention has been focussed on dental aerosol-generating procedures (AGPs) because of the coronavirus disease 2019 outbreak (COVID-19), caused by the Severe acute respiratory syndrome coronavirus 2 (SARS-CoV-2) virus. In some cases, especially when people are in close proximity to one another, COVID-19 has been proven to spread through airborne transmission $[18,19]$. The SARS-CoV-2 coronavirus can remain infectious in aerosols for extended periods, even when the water has evaporated, and particles that then settle onto surfaces can remain infectious for up to $72 \mathrm{~h}[20,21]$. The airborne transmission of SARS-CoV-2, via salivary bioaerosols, poses a significant danger to healthcare workers that operate close to the face and oral cavities, such as dental practitioners, and oral and maxillofacial surgeons, especially when carrying out AGPs [5,19,22].

It is of considerable interest to have a straightforward method to visualise and map the pattern of splatter/droplets/aerosols during AGPs. Past work has focussed mainly on the microbiological evaluation of bacteria contamination from aerosols and splatter following dental procedures, by counting aerobic bacteria colonies deposited onto agar plates positioned at various locations [23,24]. Other studies have used fluorescent tracers (such as sodium fluorescein) to show in broad terms the distribution of ejected material $[13,25]$. These methods have been used to show macro-spatial distributions of material produced by ultrasonic scalers [13], or other devices such as the high-speed air-turbine, or the triplex syringe [25]. To date, there is limited data that determined the distribution of aerosols and splatter at the microscale for the most commonly used devices, namely the ultrasonic scaler, triplex syringe, high-speed headpiece, and low-speed headpiece.

The aim of the current study was to map the microparticle distribution of splatter and aerosol contamination from routine dental procedures at defined distances using a fluorescent tracer, combined with fluorescence image analysis. The intention was to develop a model system for visualising the contamination from aerosols and splatter as a prerequisite to assessing potential mitigating measures that could reduce the extent of contamination during dental procedures.

\section{Materials and Methods}

\subsection{Experimental Setup}

The experiment was carried out in a $20 \mathrm{~m}^{2}$ PC2 laboratory. The mock dental procedures were performed on the left mandibular incisor tooth (tooth 31, FDI World Dental Federation notation), on a Columbia phantom head mannequin containing typodont model teeth in both jaws. Sodium fluorescein (Sigma-Aldrich, St Louis, MO, USA) was added into the coolant water to give a final concentration of $10 \mathrm{mg} / \mathrm{mL}$. The following types of dental equipment were used: ultrasonic piezoelectric dental scaler (Dentsply Cavitron, Charlotte, NC, USA), air-water spray triplex syringe in a portable dental cart (Forest ${ }^{\mathrm{TM}}$, Hillsboro, OR, USA), a high-speed air turbine handpiece (300,000 rpm) fitted with a tapered fissure bur (TiMax, NSK, Kanuma, Japan), and a low-speed air turbine handpiece (W\&H implantMED ${ }^{\mathrm{TM}}$, Bürmoos, Austria) (1200 rpm) fitted with a round \#5 dental bur. Representative images for each AGP are shown in Figure 1a. For the ultrasonic scaler and low-speed handpiece, the procedures were carried out for $15 \mathrm{~s}$ and $5 \mathrm{~min}$, respectively. For the high-speed handpiece and triplex syringe, the procedures were performed for $5 \mathrm{~s}$ and $15 \mathrm{~s}$, respectively. Water flow rates were adjusted as per the manufacturer's recommendations. The irrigation flow rate was $40 \mathrm{~mL} / \mathrm{min}$ for the ultrasonic scaler, $140 \mathrm{~mL} / \mathrm{min}$ 
for the triplex syringe, $15 \mathrm{~mL} / \mathrm{min}$ for the high-speed handpiece, and $15 \mathrm{~mL} / \mathrm{min}$ for the low-speed handpiece.
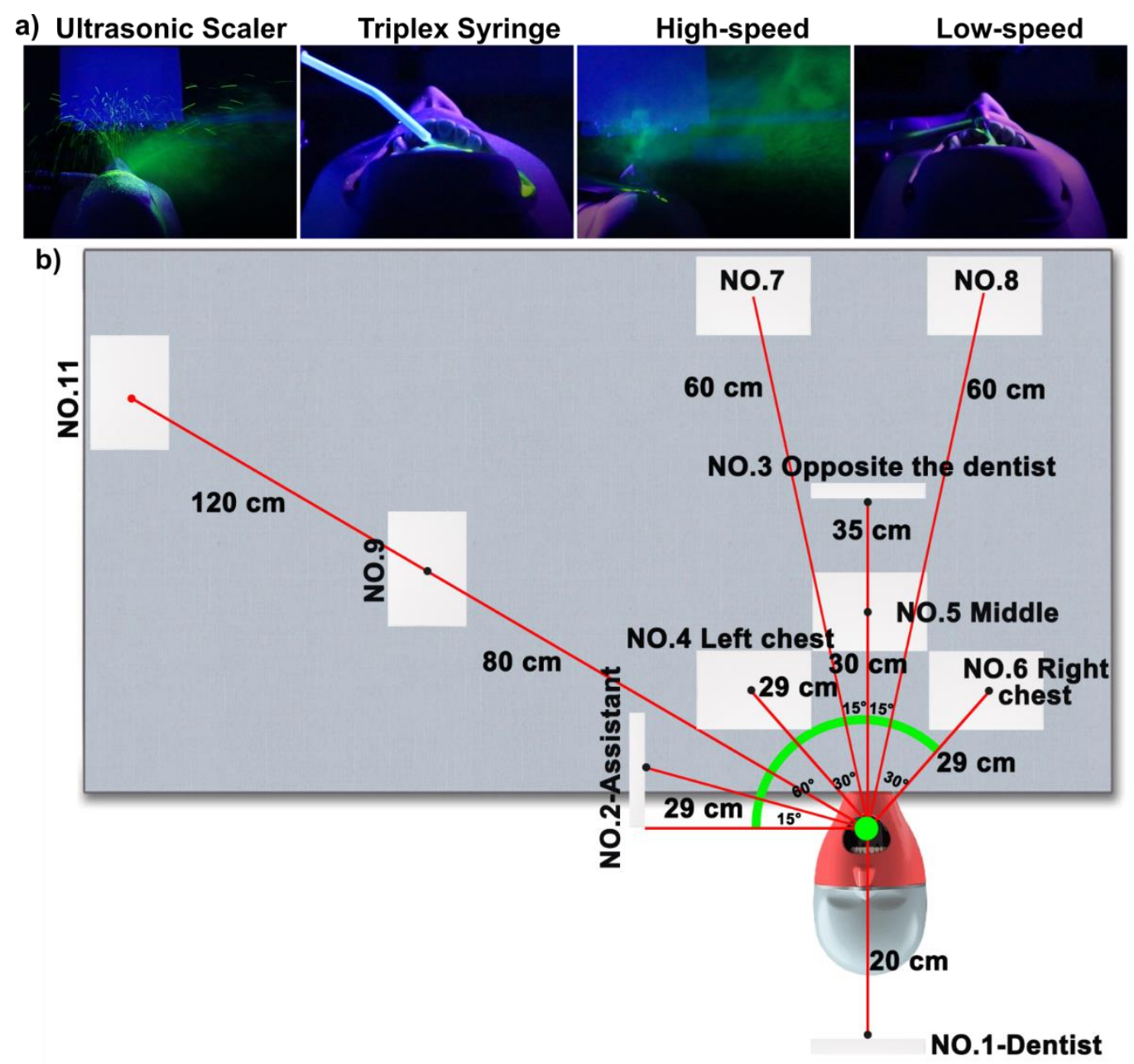

Figure 1. Representative images of liquid particles and experimental design for liquid particle collection. (a) Examples of the position of dental instruments. The fluorescein tracer is seen as green because of illumination with $405 \mathrm{~nm}$ violet light using an LED torch. The liquid generated by the ultrasonic scaler, triplex syringe, high-speed handpiece and low-speed handpiece can be seen. (b) A schematic diagram of the positions for splatter and aerosol collection at 10 different locations (No. 1-10). The angular positions in degrees were calculated relative to the sagittal plane of the mannequin.

Before each procedure, pieces of filter paper (retention size $2.00 \mu \mathrm{m}$, Filtech), with a size of 160 (length) $\times 100 \mathrm{~mm}$ (width), were placed in 10 different locations (refer to No. 1-10 in Figures 2-4), as illustrated in Figure 1b. To visualise the splatter pattern, the filter papers were visualised in a Gel Doc ${ }^{\mathrm{TM}}$ EZ Imager (Bio-Rad Laboratories Inc, USA). The aerosols retained in the filter paper fibres were imaged using a Leica DMi8 inverted fluorescent microscope (Leica Microsystems, Japan). Each experiment at each location was repeated four times. To prevent potential contamination between procedures, the whole area was cleaned between runs and $70 \%$ ethanol was used to wipe down surfaces. 


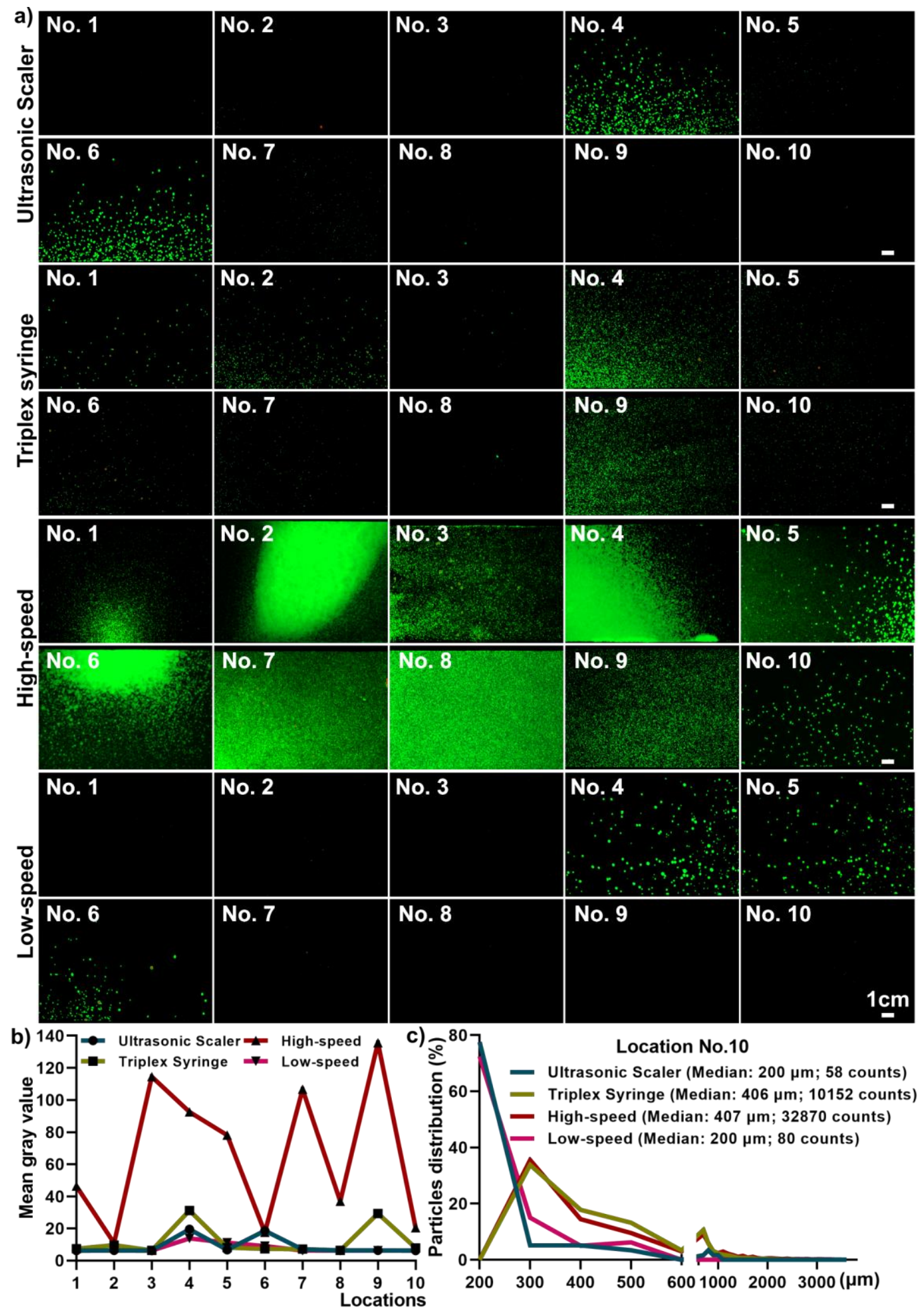

Figure 2. (a) Representative splatter images; (b) mean fluorescence intensity across 10 locations (after images were converted into grayscale); (c) particle distributions at location 10 after $15 \mathrm{~s}$ use of the ultrasonic scaler, triplex syringe, high-speed handpiece and low-speed handpiece. 


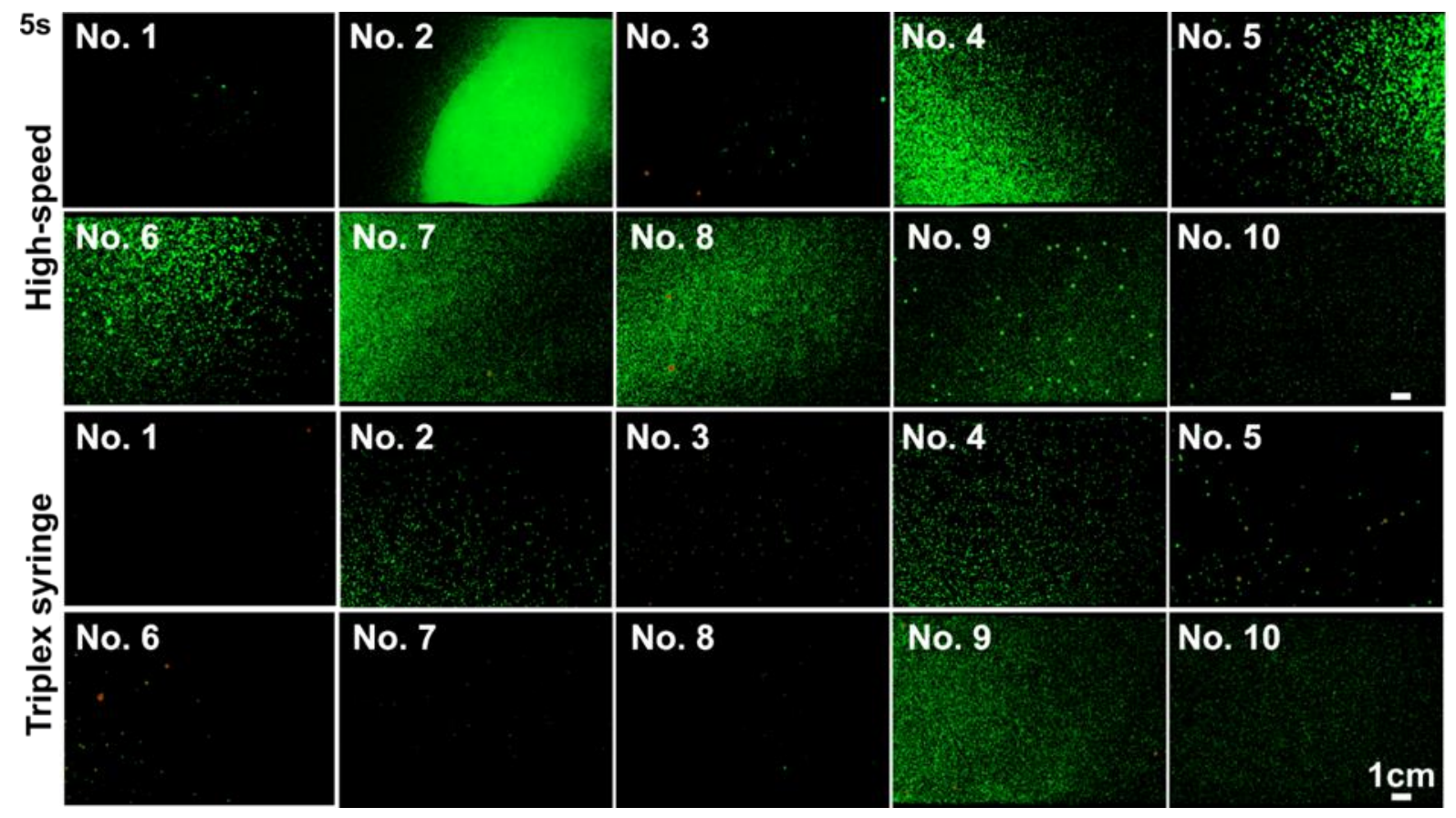

Figure 3. Splatter pattern by high-speed handpiece and triplex syringe after $5 \mathrm{~s}$.

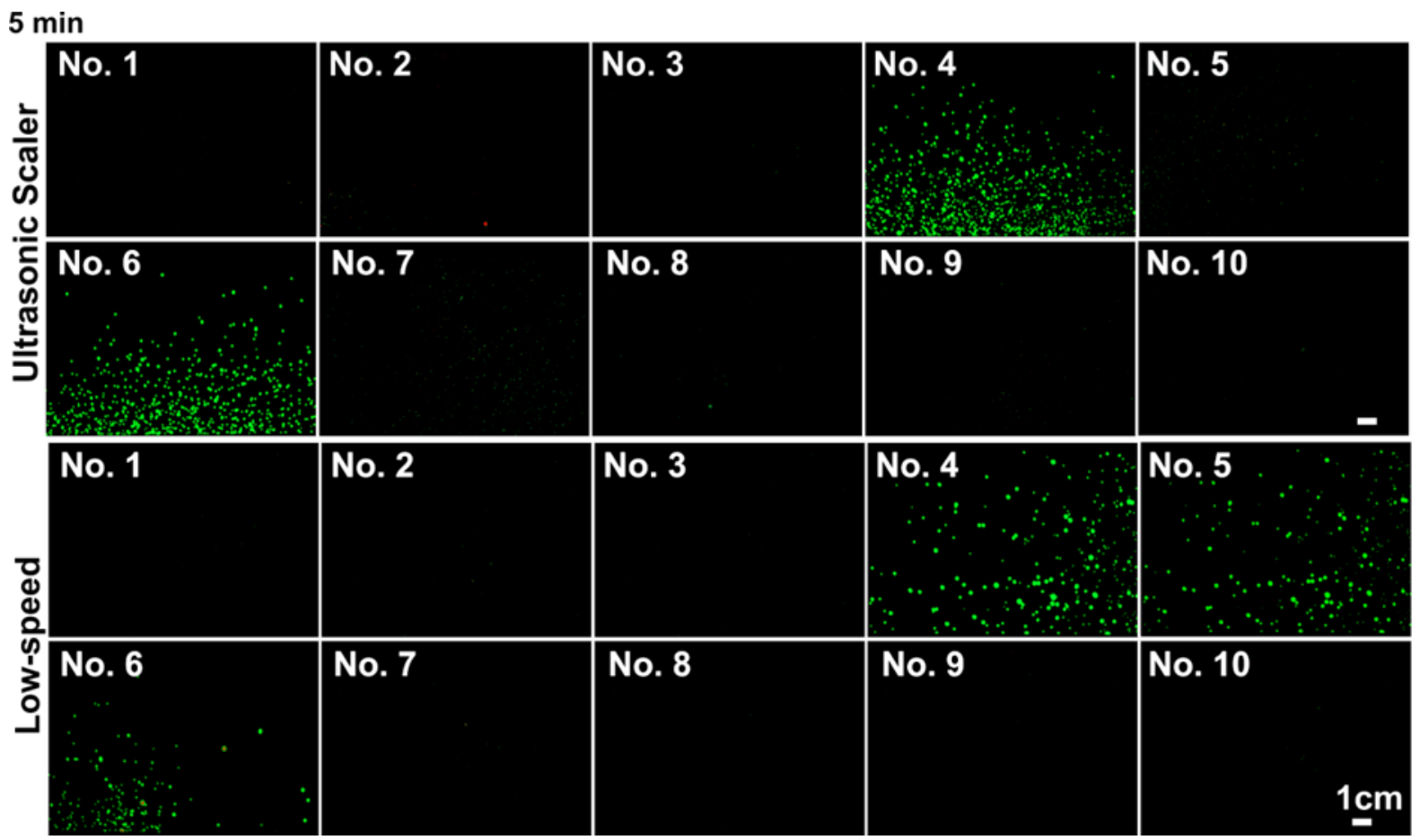

Figure 4. The splatter pattern by ultrasonic scaler and low-speed handpiece after 5 min surgeries.

\subsection{Statistical Analysis}

Images at each location were taken from four independent experiments and analysed using Fiji-ImageJ software to measure the diameter of the splatter, droplet and aerosol. For the calculation of the fluorescent value using Fiji (Figure 2b), each pixel of each fluorescent image was converted to grayscale $(0-255$; where 255 is the highest gray value) and the mean gray value was determined by the sum of the gray values of all the pixels divided by the number of 
pixels. Using GraphPad Prism software (version 9.0.0), one-way ANOVA was used to assess differences between groups, with $p$ values $<0.05$ considered statistically different.

\section{Results}

\subsection{Splatter Distribution Generated during 15 s Mock Procedures}

After $15 \mathrm{~s}$ procedures on the mandibular central incisor tooth, all four types of equipment generated liquid contamination at the various locations in the vicinity of the equipment (Figure 2). The high-speed air turbine handpiece generated the most liquid particles and contaminated all 10 collection locations, including location 10 which was $120 \mathrm{~cm}$ away from the patient (Figure 2a). After quantification of fluorescent tracer intensity, the fluorescent images were converted to grayscale in Fiji and the data showed that the high-speed handpiece showed the greatest values, being significantly higher than the other three types of equipment, at all 10 locations (Figure $2 b$ ).

The distribution of splatter particles at the furthest location (No. 10) was assessed in greater detail, focussing on the of the size and frequency of the splatter particles. The data demonstrated that the ultrasonic scaler and low-speed handpiece generated fluid splashes with smaller size particles that were less than $300 \mu \mathrm{m}$ (median diameter). In contrast, the triplex syringe and the high-speed handpiece generated larger particles $(>550 \mu \mathrm{m}$ median diameter). Most importantly, across four independent experiments, the highspeed handpiece gave the most abundant splatter contamination $(>32,000$ particles were analysed), while the ultrasonic scaler and low-speed handpiece caused less contamination (58 and 80 particles, respectively) (Figure 2c).

Furthermore, splatter particles were detected after using the high-speed handpiece and the triplex syringe for $5 \mathrm{~s}$, especially for the high-speed handpiece, which contaminated all 10 locations even after $5 \mathrm{~s}$ of use (Figure 3). On the other hand, the ultrasonic scaler and low-speed handpiece generated notable splatter contamination only at locations 4,5 and 7 after 5 min of use (Figure 4).

\subsection{Presence of Aerosols, $120 \mathrm{~cm}$ away from the Source}

The aerosol particles that were retained on the filter paper fibres were imaged at location 10 (120 cm away from the source) after $15 \mathrm{~s}$ procedures (Figure $5 \mathrm{a}$ ). Small aerosol particles (median particle diameter $<5 \mu \mathrm{m}$ ) were detected from all four equipment types (Figure 5a). The triplex syringe generated the aerosols with the smallest particle size (median diameter: $1.09 \mu \mathrm{m}$, versus $1.38 \mu \mathrm{m}$ for both the ultrasonic scaler and the highspeed handpiece). The low-speed handpiece gave the largest aerosol particles (median diameter $1.75 \mu \mathrm{m}$ ) (Figure $5 \mathrm{~b}$ ). In all four independent experiments, the triplex syringe generated the most aerosol particles ( $>7100$ particles) while the low-speed handpiece produced the least number of particles (311 particles) (Figure $5 b$ ). 

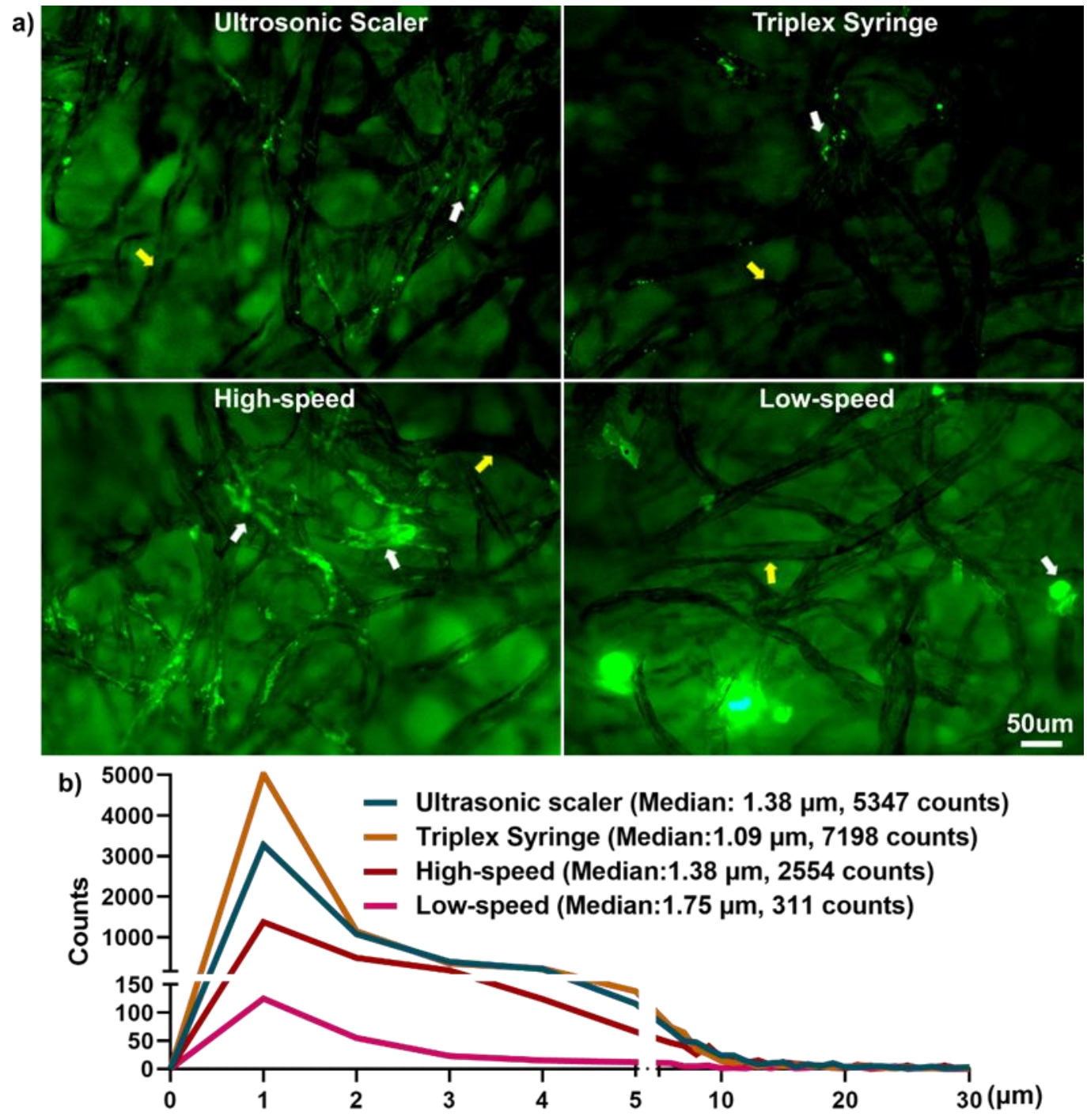

Figure 5. Detection of aerosols and droplets retained in filter paper fibres, at the furthest point from the source. (a) Representative fluorescent images of aerosols and droplets generated by four dental procedures. Yellow arrow: paper fibres; white arrow: aerosols/droplets. (b) The distribution of aerosols and droplets at location 10.

The aerosol particles were also imaged (Figure 6) at location 2 for the ultrasonic scaler and the triplex syringe (after $15 \mathrm{~s}$ ), at location 4 for the low-speed (15 s, $5 \mathrm{~min}$ ), and at location 10 for the low-speed handpiece and the triplex syringe ( $5 \mathrm{~s})$. These images (Figure $6 \mathrm{a}, \mathrm{c}, \mathrm{e})$ show that small aerosolised particles $(<5 \mu \mathrm{m})$ were detected in these locations from various equipment, with similar median particle sizes (ranging from 1.01 to $1.38 \mu \mathrm{m}$, Figure $6 \mathrm{~b}, \mathrm{~d}, \mathrm{f})$. 

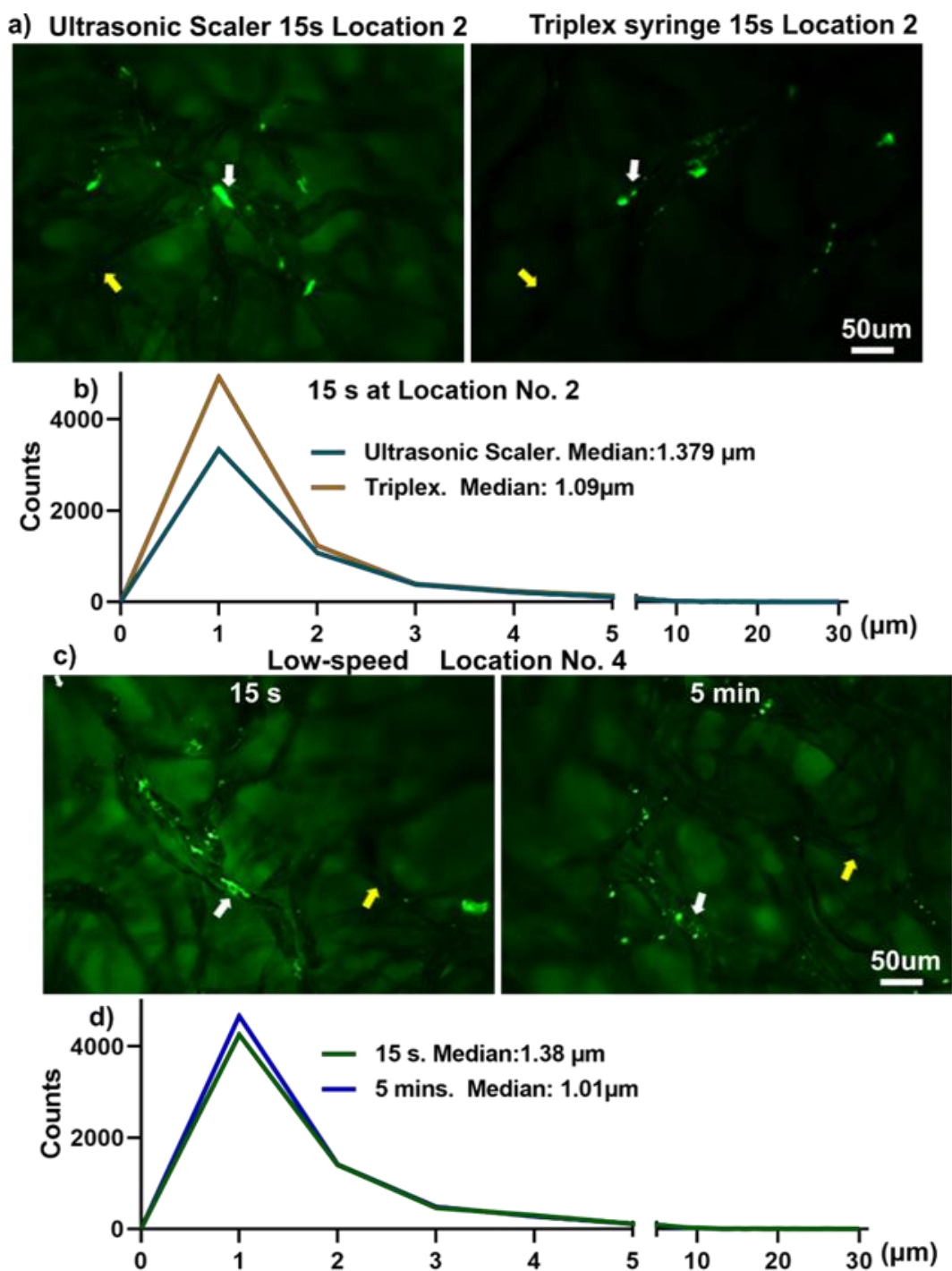

e) Triplex syringe $5 \mathrm{~s}$ Location $10 \quad$ High-speed 5 s Location 10
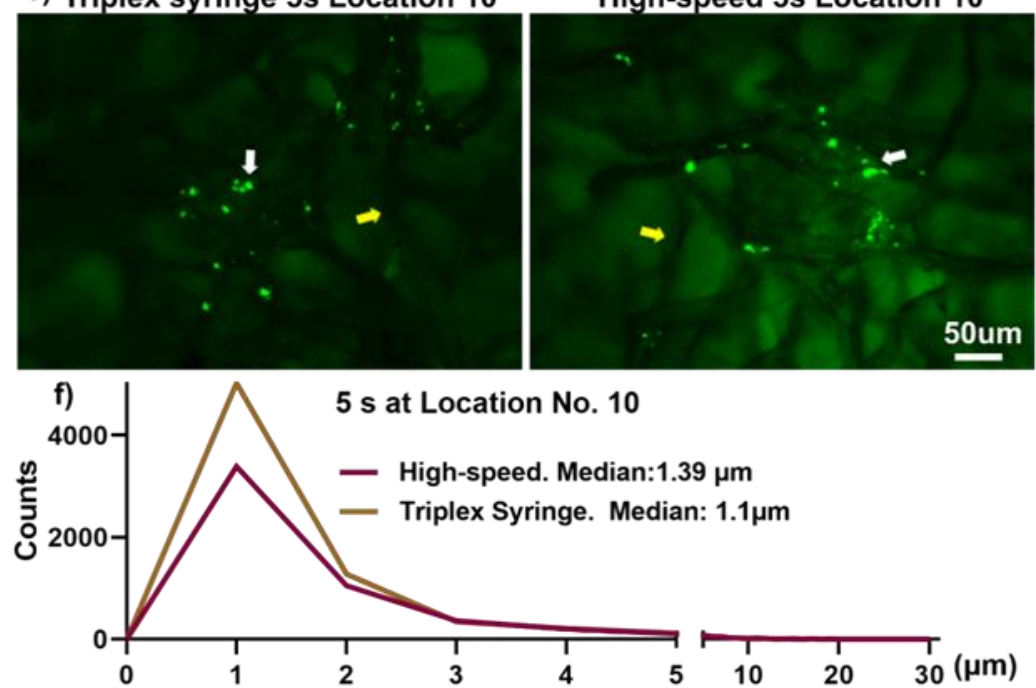

Figure 6. The visualisation (a,c,e) and histogram distributions $(\mathbf{b}, \mathbf{d}, \mathbf{f})$ of aerosols particles on the filter paper fibres. White arrow: aerosol particles; yellow arrow: paper fibres. 


\subsection{Comparison of Splatter and Aerosol Particle Size at Location 10}

The average diameter of splatter and aerosol particles at the furthest point was analysed (Figure 7). The high-speed handpiece generated significantly larger splatter particles (mean \pm SD: $656 \pm 551 \mu \mathrm{m}$, ranging from 257 to $3575 \mu \mathrm{m}$ ) than the other three types of dental equipment (Figure 7a). The splatter particles were comparable in size between the ultrasonic scaler ( $281 \pm 188 \mu \mathrm{m}$, ranging from 200 to $1020 \mu \mathrm{m}$ ) and the low-speed handpiece (260 $\pm 142 \mu \mathrm{m}$, ranging from 257 to $3497 \mu \mathrm{m}$ ), while both the triplex syringe (566 $\pm 405 \mu \mathrm{m}$, ranging from 200 to $1240 \mu \mathrm{m}$ ) and the high-speed handpiece gave significantly larger splatter compared to the ultrasonic scaler (Figure 7a).

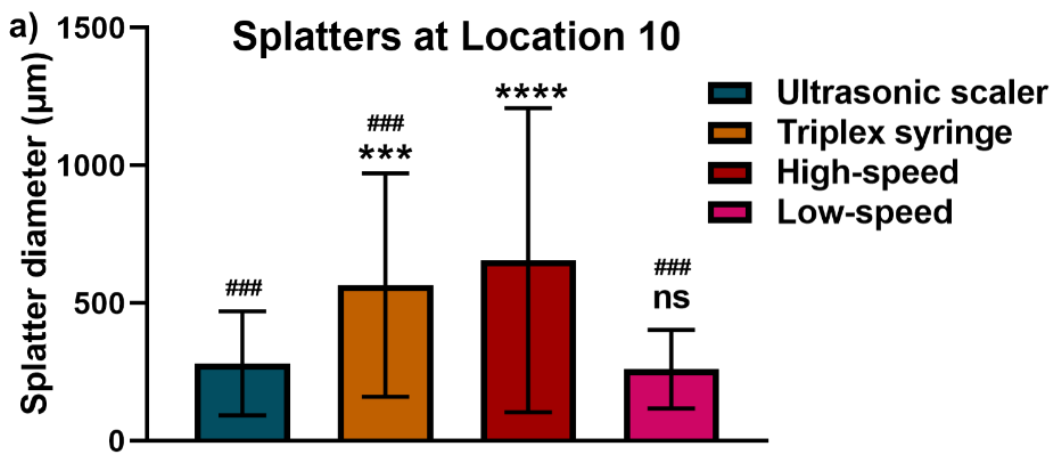

b)

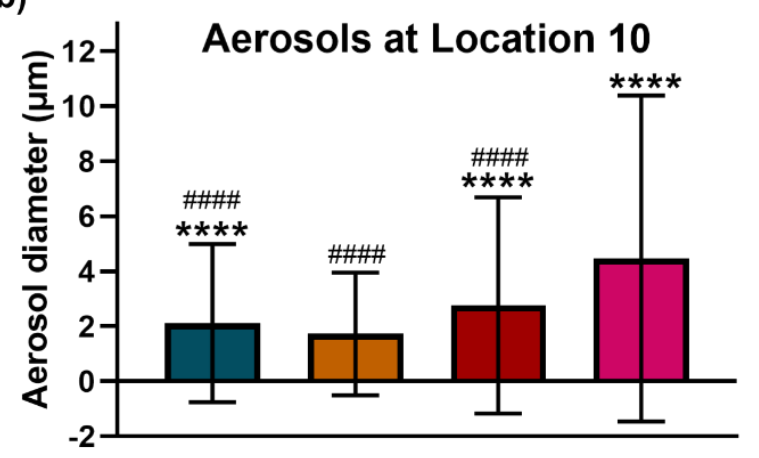

Figure 7. Average diameter of splatter (a) and aerosols/droplets (b) particles by four aerosolgenerating procedures (AGPs) at location 10. (a) Different dental AGPs generated different splatter particles at a distance $120 \mathrm{~cm}$ away from the source. ns: no significant difference. ${ }^{* * *}: p<0.0002 \mathrm{vs}$. ultrasonic scaler; $^{* * * *}: p<0.0002$ vs. ultrasonic scaler. \#\#\#: $p<0.0002$ vs. high-speed handpiece. (b) Aerosol particles difference between different AGPs. ${ }^{* * * *}: p<0.0002$ vs. triplex syringe. \#\#\#: $p<$ 0.0002 vs. low-speed handpiece.

In terms of aerosols, the low-speed handpiece generated the largest aerosol particles that were retained on the filter paper fibres (mean \pm SD: $4.47 \pm 5.92 \mu \mathrm{m}$, ranging from 0.688 to $27.2 \mu \mathrm{m}$ ), while the triplex syringe produced the smallest aerosol particles $(1.73 \pm 2.23 \mu \mathrm{m}$, ranging from 0.688 to $29.15 \mu \mathrm{m})$ (Figure $7 \mathrm{~b}$ ).

\section{Discussion}

The present study provides a useful simple model for assessing the microscale distribution of liquid particles generated by four common dental devices. The high-speed handpiece generated the most and the largest splatter particles $(>600 \mu \mathrm{m})$ at $1.2 \mathrm{~m}$ away from the source. Furthermore, aerosols $(<5 \mu \mathrm{m})$ and droplets $(<30 \mu \mathrm{m})$ were detected at $1.2 \mathrm{~m}$ away from the source, with the triplex syringe producing the greatest number of the smallest diameter aerosol particles.

The airborne spreading of splattered fluid, droplets and aerosols is a major concern in dental practice because of the risk of transmitting potentially pathogenic bacteria (such as Legionella pneumophila or Pseudomomas aeruginosa) and both oral and respiratory 
viruses [2,3,26,27], including human influenza viruses and SARS-CoV-2. Visualising and mapping the distribution of these liquid particles is important to develop preventive strategies. There is limited data available on the microscale distribution of contamination induced by aerosol-generating devices. Previous studies used fluorescein tracers [13,25] or bacterial tracers [23] to detect "bio-aerosol" contamination at up to $2 \mathrm{~m}$. However, different studies have used different definitions for aerosol and splatter particles: Allison et al. defined aerosol particles as $\leq 10 \mu \mathrm{m}$ and splatter as $>10 \mu \mathrm{m}$ in diameter [25], while Leung et al. used a cutoff value for droplets and aerosols of $5 \mu \mathrm{m}(>5 \mu \mathrm{m}-$ droplets; $\leq 5 \mu \mathrm{m}$-aerosols) [28], in the same manner as the present investigation.

The current study used a fluorescence gel imager and a microscope to capture images of splatter $(\geq 100 \mu \mathrm{m})$, droplets $(5-100 \mu \mathrm{m})$ and aerosol $(\leq 5 \mu \mathrm{m})$. Such particles were found to be generated by the ultrasonic scaler, triplex syringe, high-speed handpiece, and low-speed handpiece. All four AGPs generated considerable contamination of the patient's chest area (locations 4, 5, and 6), which is consistent with past studies with macroscale contamination pattern $[23,25]$. This patient chest contamination can be effectively dealt with using a disposable waterproof (plastic-backed) bib or apron for the patient.

The present data demonstrate that the high-speed handpiece generates the most splatter of large particles ( $>600 \mu \mathrm{m}$ in diameter) and that this contamination extends a considerable distance, at least $1.2 \mathrm{~m}$ away from the mouth. This pattern is also consistent with past work with macroscale contamination $[13,23,25,29]$.

Smaller aerosols particles $(\leq 5 \mu \mathrm{m})$ are produced by several dental procedures, and these may pose an increased risk of transmitting respiratory infections, such as COVID-19 [6,30,31]. According to the World Health Organisation (WHO) definition, airborne aerosol particles that are $<5 \mu \mathrm{m}$ in size and are generated by AGPs can remain in the air, and then travel over some distance to then cause infection if they are inhaled [12]. Our study utilised a fluorescent microscope to image the aerosol and droplet particles retained on the filter paper fibres in collection sites at $1.2 \mathrm{~m}$ away from the source. Both aerosol and droplet particles $(0.6-30 \mu \mathrm{m}$ in diameter) were generated by all four AGPs, with the triplex syringe generating the most aerosol and droplet particles, while the low-speed handpiece generated the least aerosol particles and the largest $(4.47 \pm 5.92 \mu \mathrm{m})$ aerosol particles. This indicates that all four dental AGPs need to be carefully considered in the context of planning risk-based additional precautions to prevent potential airborne transmission.

The limitation of our study is that splatter images taken by the Gel Doc imager used a relatively large size of filter paper $(160 \times 100 \mathrm{~mm})$, and the paper mesh size gave a limited resolution $(200 \mu \mathrm{m})$. Better resolution equipment is required to capture all the splatter and droplet particles. Another limitation of this study was that the water flow rate for high-speed and low-speed handpieces could be increased from $15 \mathrm{~mL} / \mathrm{min}$ (in this study) to $50 \mathrm{~mL} / \mathrm{min}$ (to mimic the real-world dental clinic) for the future studies. Furthermore, this study did not apply a high volume suction system during dental AGPs, which will be investigated as a preventative measure in future research. Notwithstanding the limitations of our study, it provides a quantitative method for visualising liquid particle contamination generated during dental AGPs. As the method demonstrates that the high-speed handpiece generated the most liquid contamination (even after $5 \mathrm{~s}$ ), the use of this item of equipment should be minimised in the clinic during the COVID-19 pandemic at times when there is community transmission. However, further research in an actual clinical environment is required to validate potential preventive strategies to mitigate airborne transmission. Testing dental high volume suction would be useful as a direction for further work using this same model. In the same manner, the model could be used to test tracers such as coloured dyes or nonharmful bacteria to show their movement. Given that saliva is more viscous than water, the laboratory model could also be used to explore how changes in the fluid density and viscosity influence the production of aerosol and splatter. 


\section{Conclusions}

This study established a method to visualise the contamination patterns of splatters, droplets and aerosols, generated by four dental AGPs. The data demonstrated that all four dental procedures generate splatter, droplets and aerosols contamination, at $120 \mathrm{~cm}$ away from the source. Among four dental AGPs, high-speed headpiece generated the most contamination. Precautions for reducing aerosol, droplet and splatter contamination from dental AGPs should be used in the treatment of all dental patients at all times.

Author Contributions: Conceptualisation, P.H., L.J.W. and S.I.; methodology, P.H., H.L.; writingoriginal draft preparation, P.H.; writing-review and editing, P.H., H.L., L.J.W. and S.I.; All authors have read and agreed to the published version of the manuscript.

Funding: This work was supported by the Australasian Osseointegration Society Limited (AOS, Qld Branch, Brisbane, Australia) and the Australian and New Zealand Academy of Periodontists (ANZAP, Sydney, Australia).

Institutional Review Board Statement: Not applicable.

Informed Consent Statement: Not applicable.

Data Availability Statement: Data available in a publicly accessible repository. The data presented in this study are openly available on MDPI website.

Acknowledgments: Not applicable.

Conflicts of Interest: The authors declare no conflict of interest.

\section{References}

1. Harrel, S.K.; Molinari, J. Aerosols and splatter in dentistry: A brief review of the literature and infection control implications. J. Am. Dent. Assoc. 2004, 135, 429-437. [CrossRef]

2. Volgenant, C.M.C.; de Soet, J.J. Cross-transmission in the dental office: Does this make you ill? Curr. Oral Health Rep. 2018, 5, 221-228. [CrossRef]

3. Zemouri, C.; de Soet, H.; Crielaard, W.; Laheij, A. A scoping review on bio-aerosols in healthcare and the dental environment. PLOS ONE 2017, 12, e0178007. [CrossRef] [PubMed]

4. Dahlke, W.O.; Cottam, M.R.; Herring, M.C.; Leavitt, J.M.; Ditmyer, M.M.; Walker, R.S. Evaluation of the spatter-reduction effectiveness of two dry-field isolation techniques. J. Am. Dent. Assoc. 2012, 143, 1199-1204. [CrossRef] [PubMed]

5. Peng, X.; Xu, X.; Li, Y.; Cheng, L.; Zhou, X.; Ren, B. Transmission routes of 2019-nCoV and controls in dental practice. Int. J. Oral Sci. 2020, 12, 9. [CrossRef] [PubMed]

6. Han, P.; Ivanovski, S. Saliva - friend and foe in the COVID-19 outbreak. Diagnostics 2020, 10, 290. [CrossRef]

7. Shiu, E.Y.C.; Leung, N.H.L.; Cowling, B.J. Controversy around airborne versus droplet transmission of respiratory viruses: Implication for infection prevention. Curr. Opin. Infect. Dis. 2019, 32, 372-379. [CrossRef]

8. Yan, J.; Grantham, M.; Pantelic, J.; Bueno de Mesquita, P.J.; Albert, B.; Liu, F.; Ehrman, S.; Milton, D.K.; Consortium, E. Infectious virus in exhaled breath of symptomatic seasonal influenza cases from a college community. Proc. Natl. Acad. Sci. USA 2018, 115, 1081-1086. [CrossRef]

9. Leggat, P.A.; Kedjarune, U. Bacterial aerosols in the dental clinic: A review. Int. Dent. J. 2001, 51, 39-44. [CrossRef]

10. James, R.; Mani, A. Dental aerosols: A silent hazard in dentistry! Int. J. Sci. Res. 2016, 5, 1761-1763.

11. Tellier, R.; Li, Y.; Cowling, B.J.; Tang, J.W. Recognition of aerosol transmission of infectious agents: A commentary. BMC Infect. Dis 2019, 19, 101. [CrossRef]

12. WHO/2019-nCoV/Oral_health/2020.1. Available online: https://www.who.int/publications/i/item/who-2019-nCoV-oralhealth-2020.1 (accessed on 21 December 2020).

13. Veena, H.R.; Mahantesha, S.; Joseph, P.A.; Patil, S.R.; Patil, S.H. Dissemination of aerosol and splatter during ultrasonic scaling: A pilot study. J. Infect. Public Health 2015, 8, 260-265. [CrossRef] [PubMed]

14. Han, P.; Bartold, P.M.; Salomon, C.; Ivanovski, S. Salivary small extracellular vesicles associated miRNAs in periodontal status - a pilot study. Int J. Mol. Sci. 2020, 21, 2809. [CrossRef] [PubMed]

15. Han, P.; Ivanovski, S. Effect of saliva collection methods on the detection of periodontium-related genetic and epigenetic biomarkers - a pilot study. Int J. Mol. Sci. 2019, 20, 4729. [CrossRef]

16. Han, P.; Lai, A.; Salomon, C.; Ivanovski, S. Detection of salivary small extracellular vesicles associated inflammatory cytokines gene methylation in gingivitis. Int. J. Mol. Sci. 2020, 21, 5273. [CrossRef] [PubMed]

17. Azzi, L.; Maurino, V.; Baj, A.; Dani, M.; d'Aiuto, A.; Fasano, M.; Lualdi, M.; Sessa, F.; Alberio, T. Diagnostic salivary tests for SARS-CoV-2. J. Dent. Res. 2020, 100. [CrossRef] 
18. National Research Council. Rapid Expert Consultation on the Possibility of Bioaerosol Spread of SARS-CoV-2 for the COVID-19 Pandemic (April 1, 2020); The National Academies Press: Washington, DC, USA, 2020. [CrossRef]

19. Tang, S.; Mao, Y.; Jones, R.M.; Tan, Q.; Ji, J.S.; Li, N.; Shen, J.; Lv, Y.; Pan, L.; Ding, P.; et al. Aerosol transmission of SARS-CoV-2? Evidence, prevention and control. Environ. Int 2020, 144, 106039. [CrossRef] [PubMed]

20. van Doremalen, N.; Bushmaker, T.; Morris, D.H.; Holbrook, M.G.; Gamble, A.; Williamson, B.N.; Tamin, A.; Harcourt, J.L.; Thornburg, N.J.; Gerber, S.I.; et al. Aerosol and surface stability of SARS-CoV-2 as compared with SARS-CoV-1. N. Engl. J. Med. 2020, 382, 1564-1567. [CrossRef] [PubMed]

21. Chin, A.W.H.; Chu, J.T.S.; Perera, M.R.A.; Hui, K.P.Y.; Yen, H.-L.; Chan, M.C.W.; Peiris, M.; Poon, L.L.M. Stability of SARS-CoV-2 in different environmental conditions. Lancet Microbe 2020, 1. [CrossRef]

22. Meng, L.; Hua, F.; Bian, Z. Coronavirus disease 2019 (COVID-19): Emerging and future challenges for dental and oral medicine. J. Dent. Res. 2020, 98. [CrossRef]

23. Ionescu, A.C.; Cagetti, M.G.; Ferracane, J.L.; Garcia-Godoy, F.; Brambilla, E. Topographic aspects of airborne contamination caused by the use of dental handpieces in the operative environment. J. l Am. Dent. Assn. 2020, 151, 660-667. [CrossRef]

24. Gund, M.; Isack, J.; Hannig, M.; Thieme-Ruffing, S.; Gärtner, B.; Boros, G.; Rupf, S. Contamination of surgical mask during aerosol-producing dental treatments. Clin. Oral Invest. 2020. [CrossRef] [PubMed]

25. Allison, J.R.; Currie, C.C.; Edwards, D.C.; Bowes, C.; Coulter, J.; Pickering, K.; Kozhevnikova, E.; Durham, J.; Nile, C.J.; Jakubovics, N.; et al. Evaluating aerosol and splatter following dental procedures: Addressing new challenges for oral health care and rehabilitation. J. Oral Rehabil. 2020, 48, 61-72. [CrossRef]

26. Kumbargere Nagraj, S.; Eachempati, P.; Paisi, M.; Nasser, M.; Sivaramakrishnan, G.; Verbeek, J.H. Interventions to reduce contaminated aerosols produced during dental procedures for preventing infectious diseases. Cochrane Database Syst. Rev. 2020. [CrossRef]

27. Lu, J.; Gu, J.; Li, K.; Xu, C.; Su, W.; Lai, Z.; Zhou, D.; Yu, C.; Xu, B.; Yang, Z. COVID-19 outbreak associated with air conditioning in restaurant, Guangzhou, China, 2020. Emerg. Infect. Dis. 2020, 26, 1628-1631. [CrossRef]

28. Leung, N.H.L.; Chu, D.K.W.; Shiu, E.Y.C.; Chan, K.H.; McDevitt, J.J.; Hau, B.J.P.; Yen, H.L.; Li, Y.; Ip, D.K.M.; Peiris, J.S.M.; et al. Respiratory virus shedding in exhaled breath and efficacy of face masks. Nat. Med. 2020, 26, 676-680. [CrossRef] [PubMed]

29. Rautemaa, R.; Nordberg, A.; Wuolijoki-Saaristo, K.; Meurman, J.H. Bacterial aerosols in dental practice-A potential hospital infection problem? J. Hospital Infect. 2006, 64, 76-81. [CrossRef]

30. Alsved, M.; Matamis, A.; Bohlin, R.; Richter, M.; Bengtsson, P.E.; Fraenkel, C.J.; Medstrand, P.; Löndahl, J. Exhaled respiratory particles during singing and talking. Aerosol Sci. Technol. 2020, 54, 1245-1248. [CrossRef]

31. Morawska, L.; Milton, D.K. It is time to address airborne transmission of coronavirus disease 2019 (COVID-19). Clin. Infect. Dis. 2020, 71, 2311-2313. [CrossRef] [PubMed] 